\title{
Oxidation of Tetracaine Hydrochloride by Chloramine-B in Acid Medium: Kinetic Modeling
}

\author{
Jayachamarajapura Pranesh Shubha ${ }^{1}$ and Puttaswamy ${ }^{2}$ \\ ${ }^{1}$ Department of Chemistry, Don Bosco Institute of Technology, Kumbalagodu, Bangalore 560 074, India \\ ${ }^{2}$ Department of Chemistry, Bangalore University, Central College, Bangalore 560 001, India \\ Correspondence should be addressed to Jayachamarajapura Pranesh Shubha; shubhapranesh@gmail.com
}

Received 20 August 2013; Revised 22 October 2013; Accepted 5 November 2013; Published 10 February 2014

Academic Editor: Francesco Paolucci

Copyright (c) 2014 J. P. Shubha and Puttaswamy. This is an open access article distributed under the Creative Commons Attribution License, which permits unrestricted use, distribution, and reproduction in any medium, provided the original work is properly cited.

\begin{abstract}
Tetracaine hydrochloride $(\mathrm{TCH})$ is one of the potent local anaesthetics. A kinetic study of oxidation of tetracaine hydrochloride by sodium $\mathrm{N}$-chlorobenzenesulfonamide (chloramine- $\mathrm{B}$ or $\mathrm{CAB}$ ) has been carried in $\mathrm{HClO}_{4}$ medium at $303 \mathrm{~K}$. The rate shows firstorder dependence on $[\mathrm{CAB}]_{0}$, shows fractional-order dependence on [substrate $]_{0}$, and is self-governing on acid concentration. Decrease of dielectric constant of the medium, by adding methanol, increased the rate. Variation of ionic strength and addition of benzenesulfonamide or $\mathrm{NaCl}$ have no significant effect on the rate. The reaction was studied at different temperatures and the activation parameters have been evaluated. The stoichiometry of the reaction was found to be $1: 5$ and the oxidation products were identified by spectral analysis. The conjugate free acid $\mathrm{C}_{6} \mathrm{H}_{5} \mathrm{SO}_{2} \mathrm{NHCl}$ of $\mathrm{CAB}$ is postulated as the reactive oxidizing species. The observed results have been explained by plausible mechanism and the related rate law has been deduced.
\end{abstract}

\section{Introduction}

Local anesthetics are drugs which produce reversible blockade of nerve impulse conduction. They act directly on specific receptors on sodium channels inhibiting sodium ion influx. Local anesthetics are valued for the ability to avoid membrane depolarization [1]. Tetracaine hydrochloride [2-dimethylaminoethy-4-n-butylaminobenzoate hydrochloride, $\mathrm{TCH}$ ], an ester of $\mathrm{p}$-aminobenzoic acid, has been widely used as local anaesthetic and is long-standing agent for spinal anaesthesia. In biomedical research, TCH is used to modify the function of calcium release channels (ryanodine receptors) that control the release of calcium from intracellular stores. TCH is an allosteric blocker of channel function. At low concentrations, TCH causes an initial inhibition of spontaneous calcium release events, while at high concentrations, TCH blocks release completely $[2,3]$. Hence tetracaine hydrochloride forms one of the important drugs in pharmaceutical industry. After reviewing the literature, we found that there was no information available on the oxidation kinetics of TCH with any oxidant. Therefore the title investigation was undertaken.
The miscellaneous nature of chemistry of N-haloamines is a significance of their aptitude to act as sources of species, such as halonium cations, hypohalites, and $\mathrm{N}$-anions which act as bases, nucleophiles, and nutrenoids [3-7]. They behave as mild oxidants and are suitable for the partial oxidation of several groups. As a result, these reagents react with a selection of functional groups distressing an array of molecular transformations. In general, monohaloamines undergo two electron changes while dihaloamines are four-electron oxidants [3]. The reduction products are the respective sulfonamide and $\mathrm{NaCl}$ or $\mathrm{HCl}$. The outstanding member of this class of compounds is chloramine-T (CAT) and the other member is chloramine- $\mathrm{B}$ (sodium $\mathrm{N}$-chlorobenzenesulfonamide or $\mathrm{CAB})$. The $\mathrm{N}-\mathrm{Cl}$ bond in $\mathrm{CAT}$ and $\mathrm{CAB}$ is highly polar and hence these two compounds are fairly strong electrophiles, since chlorine leaves as $\mathrm{Cl}^{+}$in these reactions. CAT has been used for the oxidation of a variety of organic and inorganic substrates and the oxidation mechanisms have been kinetically well investigated $[5,6]$. But there is meager information available in literature $[7,8]$ on the use of CAB. $\mathrm{CAB}$ is a stable compound with slightly higher active chlorine content than its analogue CAT. CAB is gaining importance as 
a mild oxidant and hence there is a considerable scope for the extension of work with $\mathrm{CAB}$ to get better insight of the speciation of $\mathrm{CAB}$ reaction models and deliberate its redox chemistry in solution.

In the glow of the available information and in continuationof work on oxidation studies with organic chloramines in general and medicinal compounds in particular, the present investigations were undertaken. The main objectives of the present study are to (i) explicate plausible mechanisms, (ii) deduce suitable rate laws, and (iii) determine the various reactive species.

\section{Experimental}

2.1. Materials. An aqueous solution of CAB (Merck) was prepared and stored in brown bottles to prevent its photochemical deterioration [9]. TCH (Alfa Chem) was used as received and an aqueous solution of TCH was freshly prepared whenever required. Solvent isotope studies were made with $\mathrm{D}_{2} \mathrm{O}, 99.4 \%$ supplied by BARC, Mumbai, India. Analytical grade chemicals and double distilled water were used throughout. Regression coefficient $(r)$ was calculated using fx-350 TL scientific calculator.

2.2. Kinetic Procedure. Reactions were carried out under pseudo-first-order conditions were maintained for the kinetic runs $\left([\text { substrate }]_{0} \gg[\text { oxidant }]_{0}\right)$ at constant temperature $303 \mathrm{~K}$ in glass stoppered Pyrex boiling tubes coated black fromoutside to eliminate photochemical deterioration. A Raaga digital proportional temperature controller $(\mathrm{CH}-16)$ was used to maintain the desired temperature with an accuracy of $\pm 0.1^{\circ} \mathrm{C}$. The requisite amounts of solutions of substrate and $\mathrm{HClO}_{4}$ solutions and water (for constant total volume) for all kinetic runs were equilibrated at $303 \mathrm{~K}$ for about $30 \mathrm{~min}$. A measured amount of CAB also equilibrated at the same temperature was rapidly added to the reaction mixture which was periodically shaken for uniform concentration. The improvement of the reaction was monitored by withdrawing measured aliquots $(5 \mathrm{~mL}$ each) from the reaction mixture at regular time intervals and determined the unreacted $\mathrm{CAB}$ iodometrically. The course of the reaction was studied more than two half-lives. The pseudo-first-order rate constants $\left(k^{\prime} \mathrm{s}^{-1}\right)$ calculated from the linear plots of $\log [\mathrm{CAB}]$ versus time were reproducible within $\pm 3-4 \%$.

2.3. Stoichiometry. Varying ratios of $\mathrm{CAB}$ to $\mathrm{TCH}$ were equilibriated at $303 \mathrm{~K}$ for $24 \mathrm{~h}$ in the presence of $\mathrm{mol} \mathrm{dm}^{-3}$ $\mathrm{HClO}_{4}$. The residual oxidant was determined by iodometry and the analysis showed that one mole of TCH consumed 5 moles of $\mathrm{CAB}$ as

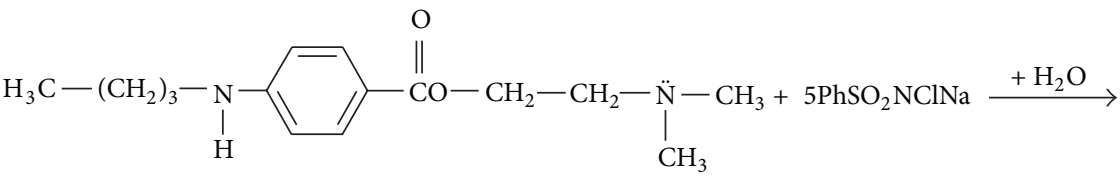

$$
\begin{aligned}
& \mathrm{NH}\left(\mathrm{CH}_{3}\right)_{2}+\mathrm{OH}-\mathrm{CH}_{2}-\mathrm{COOH}+\mathrm{H}_{3} \mathrm{C}-\mathrm{CH}_{2}-\mathrm{CH}_{2}-\underset{\mathrm{OH}}{\mathrm{C}}=\mathrm{O}+\mathrm{H}_{2} \mathrm{~N} \\
& +5 \mathrm{PhSO}_{2} \mathrm{NH}_{2}+5 \mathrm{Na}^{+}+5 \mathrm{Cl}^{-} \text {. }
\end{aligned}
$$

2.4. Product Analysis. The TCH-CAB reaction mixture in the stoichiometric ratio in the presence of $\mathrm{HClO}_{4}$ under stirred condition was allowed to progress for $24 \mathrm{~h}$ at $303 \mathrm{~K}$. After completion of the reaction (monitored by TLC), the reaction products were neutralized with $\mathrm{NaOH}$ and extracted with ether. The organic products were subjected to spot tests and chromatographic analysis (TLC technique) which revealed the formation of p-aminobenzoic acid (Figure 1), dimethylamine, and glycolic acid. These oxidation products were separated by column chromatography and were confirmed by GCMS analysis (molecular ion peak at 45, 76, 88, and $137 \mathrm{amu}$ (Figure 1). It was also noticed that there was no further oxidation of these products under current kinetic conditions.

The reaction product of $\mathrm{CAB}$, benzenesulfonamide, $\left(\mathrm{PhSO}_{2} \mathrm{NH}_{2}\right)$ was detected [7] by thin layer chromatography, using light petroleum-chloroform-butan-1-ol $(2: 2: 1 \mathrm{v} / \mathrm{v} / \mathrm{v})$ as the solvent and iodine as the detecting agent $\left(R_{f}=0.88\right)$ and also confirmed by GCMS analysis (157 amu).

\section{Results and Discussion}

The kinetics of oxidation of $\mathrm{TCH}$ by $\mathrm{CAB}$ was investigated at several initial concentrations of the reactants at $303 \mathrm{~K}$. Under pseudo-first-order conditions of $[\text { substrate }]_{0} \gg{\text { [oxidant }]_{0}}_{0}$ at constant $\left[\mathrm{HClO}_{4}\right]$ and temperature, plots of log $[\mathrm{CAB}]$ versus time were linear $(r>0.9925)$ indicating a firstorder dependence of rate on $[\mathrm{CAB}]_{0}$. The pseudo-first-order rate constants $\left(k^{\prime}\right)$ calculated from these plots are given in Table 1. Further, the values of $k^{\prime}$ calculated from these plots are unaltered with variation of $[\mathrm{CAB}]_{0}$, confirming the firstorder dependence on $[\mathrm{CAB}]_{0}$. The rate increased with the increase in [substrate] (Table 1). A plot of $\log k^{\prime}$ versus $\log [\mathrm{TCH}]$ was linear $(r=0.9892$, Figure 3$)$ with a slope 


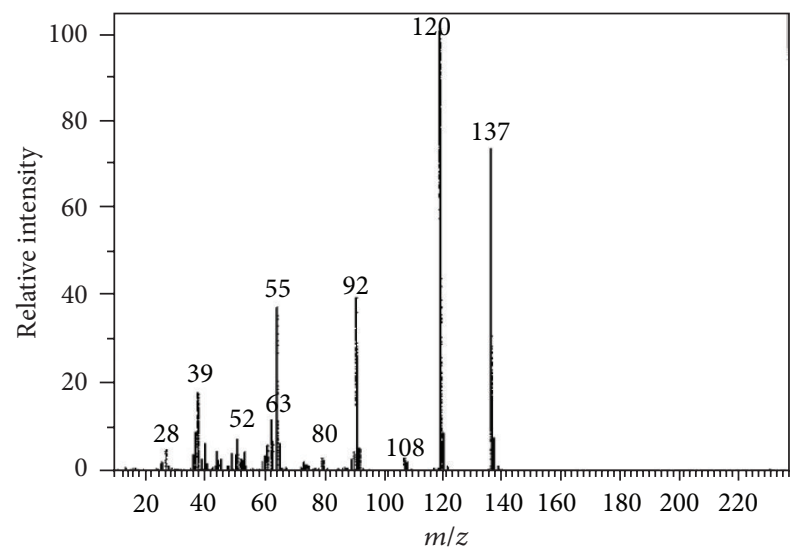

FIGURE 1: GC-mass spectrum of p-aminobenzoic acid with its molecular ion peak at $137 \mathrm{amu}$.

TABLE 1: Effect of varying $\mathrm{CAB}, \mathrm{TCH}$, and $\mathrm{HClO}_{4}$ concentrations on reaction at $303 \mathrm{~K}$.

\begin{tabular}{lccc}
\hline $\begin{array}{l}10^{3}[\mathrm{CAB}]_{\circ} \\
\left(\mathrm{mol} \mathrm{dm}^{-3}\right)\end{array}$ & $\begin{array}{c}10^{2}[\mathrm{TCH}] \\
\left(\mathrm{mol} \mathrm{dm}^{-3}\right)\end{array}$ & $\begin{array}{c}10\left[\mathrm{HClO}_{4}\right] \\
\left(\mathrm{mol} \mathrm{dm}^{-3}\right)\end{array}$ & $\begin{array}{c}10^{4} k^{\prime} \\
\left(\mathrm{s}^{-1}\right)\end{array}$ \\
\hline 0.5 & 2.0 & 2.0 & 7.65 \\
1.0 & 2.0 & 2.0 & 7.55 \\
2.0 & 2.0 & 2.0 & 7.95 \\
4.0 & 2.0 & 2.0 & 7.80 \\
6.0 & 2.0 & 2.0 & 7.87 \\
2.0 & 0.5 & 2.0 & 4.66 \\
2.0 & 1.0 & 2.0 & 6.46 \\
2.0 & 2.0 & 2.0 & 7.95 \\
2.0 & 3.0 & 2.0 & 10.1 \\
2.0 & 4.0 & 2.0 & 12.3 \\
2.0 & 2.0 & 0.5 & 8.25 \\
2.0 & 2.0 & 1.0 & 7.93 \\
2.0 & 2.0 & 2.0 & 7.95 \\
2.0 & 2.0 & 3.0 & 8.13 \\
2.0 & 2.0 & 4.0 & 7.88 \\
\hline
\end{tabular}

of 0.46 indicating a fractional-order dependence of the rate on $[\mathrm{TCH}]_{0}$. Furthermore, a plot of $k^{\prime}$ versus $[\mathrm{TCH}]_{0}$ is linear $(r=0.9864$, Figure 4$)$ with $y$-intercept, confirming fractional-order dependence on [substrate $]_{0}$. Values of $k^{\prime}$ are unaffected with the increase in $\left[\mathrm{HClO}_{4}\right]$, indicating a zeroorder dependence of rate on $\left[\mathrm{H}^{+}\right]$(Table 1 ).

Addition of the reaction product, benzenesulfonamide, $\left(2.0 \times 10^{-4}-6.0 \times 10^{-4} \mathrm{~mol} \mathrm{dm}{ }^{-3}\right)$ and addition of $\mathrm{Cl}^{-}$ion $\left(4.0 \times 10^{-2}-8.0 \times 10^{-2} \mathrm{~mol} \mathrm{dm}^{-3}\right)$ in the form of $\mathrm{NaCl}$ had no significant effect on the rate. The effect of ionic strength of the medium was studied by varying the sodium perchlorate concentration in a range of $0.10-0.30 \mathrm{~mol} \mathrm{dm}^{-3}$ by keeping the other experimental conditions constant. It was found that ionic strength has a negligible effect on the reaction rate. Hence no attempt was made to keep ionic strength constant for kinetic runs.

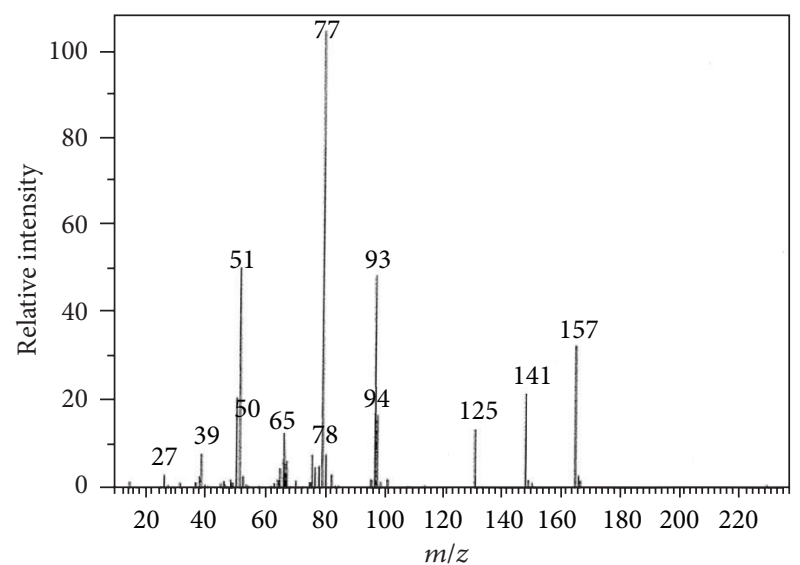

FIgURE 2: GC-Mass spectrum of benzenesulfonamide with its molecular ion peak at $157 \mathrm{amu}$.

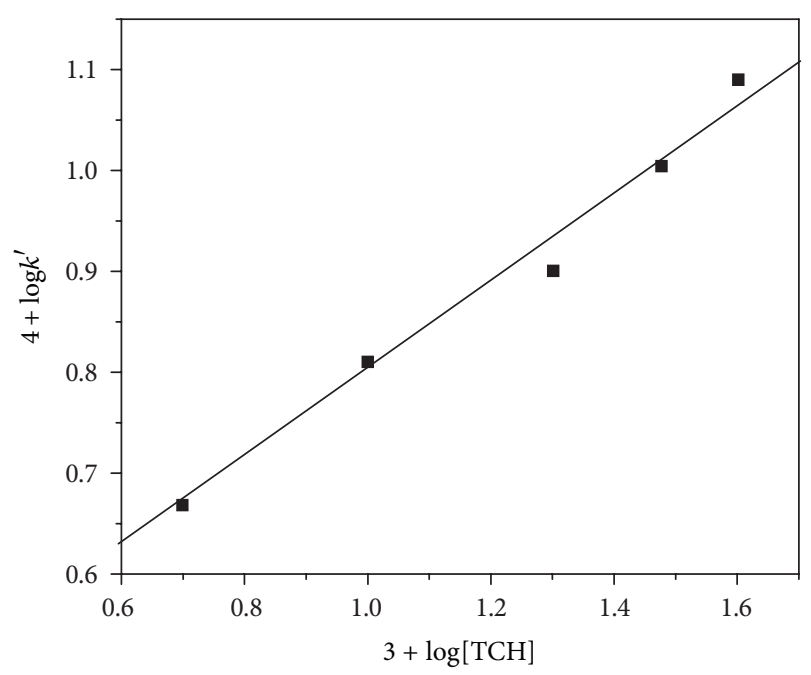

Figure 3: Plot of $\log k^{\prime}$ versus $\log [\mathrm{TCH}]$.

TABLE 2: Effect of varying dielectric constant of medium on the reaction rate at $[\mathrm{CAB}]_{\mathrm{o}}=2.0 \times 10^{-3} \mathrm{~mol} \mathrm{dm}^{-3} ;[\mathrm{TCH}]_{\mathrm{o}}=2.0 \times$ $10^{-2} \mathrm{~mol} \mathrm{dm}^{-3}$; and $\left[\mathrm{HClO}_{4}\right]=0.2 \mathrm{~mol} \mathrm{dm}{ }^{-3}$; temp $=303 \mathrm{~K}$.

\begin{tabular}{lcc}
\hline$\% \mathrm{MeOH}(\mathrm{v} / \mathrm{v})$ & $D$ & $10^{4} k^{\prime}\left(\mathrm{s}^{-1}\right)$ \\
\hline 0 & 76.73 & 7.95 \\
5 & 74.50 & 8.42 \\
10 & 72.37 & 9.75 \\
20 & 67.48 & 11.4 \\
30 & 62.71 & 12.7 \\
40 & 58.06 & 15.9 \\
\hline
\end{tabular}

The effect of dielectric constant $(D)$ on the reaction rate was studied by adding various proportions of methanol $(0-$ $40 \% \mathrm{v} / \mathrm{v}$ ) to the reacting system. It was observed that an increase in methanol composition in the reaction system 
TABLE 3: Effect of varying temperature on the reaction rate and activation parameters for the oxidation of tetracaine hydrochloride

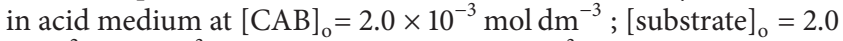
$\times 10^{-2} \mathrm{~mol} \mathrm{dm}^{-3}$; and $\left[\mathrm{HClO}_{4}\right]=0.2 \mathrm{~mol} \mathrm{dm}^{-3}$.

\begin{tabular}{lc}
\hline Temperature $(\mathrm{K})$ & $10^{4} k^{\prime}\left(\mathrm{s}^{-1}\right)$ \\
\hline 283 & 4.56 \\
293 & 6.31 \\
303 & 7.95 \\
313 & 10.3 \\
323 & 13.6 \\
$E_{a} / \mathrm{kJ} \mathrm{mol}^{-1}$ & 46.0 \\
$\Delta H^{\neq} / \mathrm{kJ} \mathrm{mol}^{-1}$ & 43.7 \\
$\Delta G^{\neq} / \mathrm{kJ} \mathrm{mol}^{-1}$ & 93.2 \\
$\Delta S^{\neq} / \mathrm{JK}^{-1} \mathrm{~mol}^{-1}$ & -159 \\
\hline
\end{tabular}

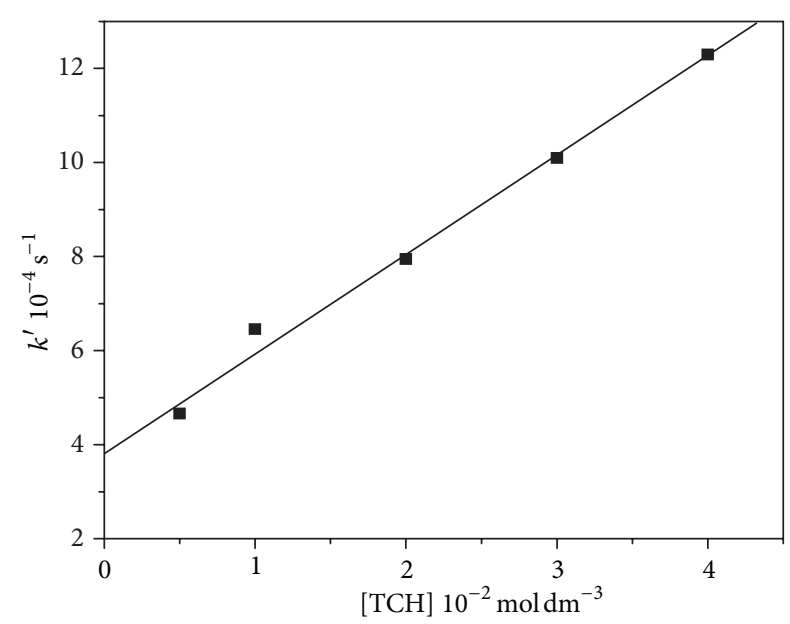

Figure 4: Plot of $k^{\prime}$ versus [TCH].

increased the reaction rate (Table 2) and a plot of $\log k^{\prime}$ versus $1 / D$ was linear (Figure $5 ; r=0.9926$ ) with a positive slope. The values of permittivity (dielectric constant) for $\mathrm{MeOH}$ water mixtures reported in the literature were employed [9]. Blank experiments run with methanol indicated negligible oxidation under the experimental conditions employed. The solvent isotope effect was studied in $\mathrm{D}_{2} \mathrm{O}$, where $k^{\prime}=7.95 \times$ $10^{-4} \mathrm{~s}^{-1}$ in $\mathrm{D}_{2} \mathrm{O}$ medium and $7.95 \times 10^{-4} \mathrm{~s}^{-1}$ in water leading to a solvent isotope effect, $k^{\prime}\left(\mathrm{H}_{2} \mathrm{O}\right) / k^{\prime}\left(\mathrm{D}_{2} \mathrm{O}\right)=1.07$.

The reaction was studied at different temperatures (283-323 K), keeping other experimental conditions constant. From the linear Arrhenius plot of $\log k^{\prime}$ versus $1 / T$ $(r=0.9921$, Figure 6), values of activation parameters $\left(E_{a}, \Delta H^{\neq}, \Delta S^{\neq}\right.$, and $\left.\Delta G^{\neq}\right)$for the overall reaction were computed. These results are compiled in Table 3. Absence of free radicals during the course of oxidation was confirmed when no polymerization was initiated with the addition of acrylonitrile solution to the reaction mixture.

$\mathrm{CAB}$ is analogous to $\mathrm{CAT}$ and exhibits similar equilibria in aqueous acidic and basic solutions $[5,8,10,11]$. In general, $\mathrm{CAB}$ undergoes a two-electron change in its reactions forming the reduction products, benzenesulfonamide (BSA; $\mathrm{PhSO}_{2} \mathrm{NH}_{2}$ ) and $\mathrm{NaCl}$. The oxidation potential of CAB-BSA

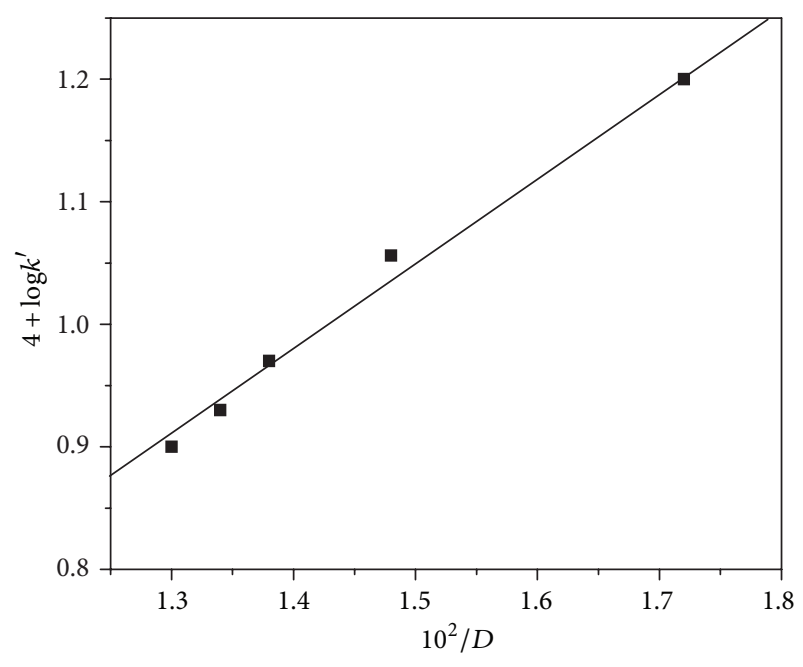

Figure 5: Plot of $\log k^{\prime}$ versus $1 / D$.

redox couple varies [12] with $\mathrm{pH}$ of the medium (values are $1.14 \mathrm{~V}$ at $\mathrm{pH} 0.65$ and $0.50 \mathrm{~V}$ at $\mathrm{pH} 12$ ). Aqueous solution of $\mathrm{CAB}$ behaves as a strong electrolyte and, depending on the $\mathrm{pH}, \mathrm{CAB}$ furnishes different types of reactive species

$$
\begin{gathered}
\mathrm{PhSO}_{2} \mathrm{NClNa} \rightleftharpoons \mathrm{PhSO}_{2} \mathrm{NCl}^{-}+\mathrm{Na} \\
\mathrm{PhSO}_{2} \mathrm{NCl}^{-}+\mathrm{H}^{+} \rightleftharpoons \mathrm{PhSO}_{2} \mathrm{NHCl} \\
2 \mathrm{PhSO}_{2} \mathrm{NHCl} \rightleftharpoons \mathrm{PhSO}_{2} \mathrm{NH}_{2}+\mathrm{PhSO}_{2} \mathrm{NCl}_{2} \\
\mathrm{PhSO}_{2} \mathrm{NCl}_{2}+\mathrm{H}_{2} \mathrm{O} \rightleftharpoons \mathrm{PhSO}_{2} \mathrm{NHCl}+\mathrm{HOCl} \\
\mathrm{PhSO}_{2} \mathrm{NHCl}+\mathrm{H}_{2} \mathrm{O} \rightleftharpoons \mathrm{PhSO}_{2} \mathrm{NH}_{2}+\mathrm{HOCl} \\
\mathrm{HOCl} \rightleftharpoons \mathrm{H}^{+}+\mathrm{OCl}^{-} \\
\mathrm{HOCl}+\mathrm{H}^{+} \rightleftharpoons \mathrm{H}_{2} \mathrm{OCl}^{+}
\end{gathered}
$$

Therefore, the possible oxidizing species in acid solution of $\mathrm{CAB}$ are $\mathrm{PhSO}_{2} \mathrm{NHCl}, \mathrm{PhSO}_{2} \mathrm{NCl}_{2}, \mathrm{HOCl}$, and possibly $\mathrm{H}_{2} \mathrm{OCl}^{+}$and, in alkaline $\mathrm{CAB}$ solutions, they are $\mathrm{PhSO}_{2} \mathrm{NHCl}, \mathrm{PhSO}_{2} \mathrm{NCl}^{-}, \mathrm{HOBr}$, and $\mathrm{OBr}^{-}$.

The first-order dependence of rate on $[\mathrm{CAB}]_{\mathrm{o}}$ and the addition of benzenesulfonamide $\left(\mathrm{PhSO}_{2} \mathrm{NH}_{2}\right)$ having no effect on the reaction rate both indicate that $\mathrm{PhSO}_{2} \mathrm{NCl}_{2}$ and $\mathrm{HOCl}$ may not be the reactive species (4) and (6). Further, these species are present in very low concentrations at the experimental conditions employed. Furthermore, variation of $\left[\mathrm{H}^{+}\right]$, ionic strength of the medium, and addition of the reaction product, benzenesulfonamide, have virtually no effect on the rate.

Based on the above discussion and experimental observation, the following general scheme involving the direct interaction of the substrate with $\mathrm{PhSO}_{2} \mathrm{NHCl}$ (Scheme 1) is proposed. A fractional order dependence on [substrate] indicates a prior equilibrium followed by the rate determining step.

In Scheme $1, \mathrm{X}$ is a CAB-TCH complex species and $\mathrm{X}^{\prime}$ is another intermediate complex species whose structures 


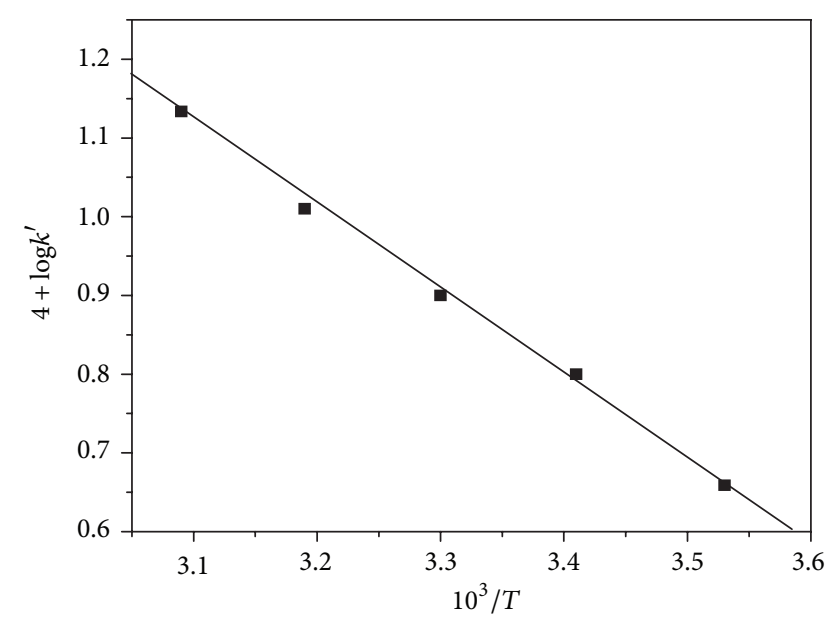

Figure 6: Plot of $\log k^{\prime}$ versus $1 / T$.

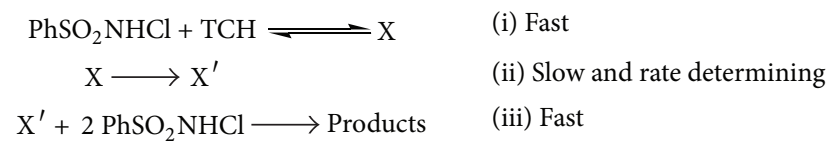

Scheme 1: A general mechanistic scheme for the oxidation of tetracaine hydrochloride by $\mathrm{CAB}$ in acid medium.

are shown in Scheme 2, where a detailed mechanistic interpretation of procaine hydrochloride oxidation by $\mathrm{CAB}$ in acid medium is proposed. In this, the conjugate-free acid $\left(\mathrm{PhSO}_{2} \mathrm{NHCl}\right)$ directly reacts with the substrate in a fast equilibrium step to form the substrate-oxidant complex $(X)$. This decomposes in a rate-determining step to the products. Five moles of the oxidant is consumed to yield the ultimate products.

Step (ii) of Scheme 1 determines the overall rate,

$$
\text { rate }=\frac{-d[\mathrm{CAB}]}{d t}=k_{2}[\mathrm{X}]
$$

If $[\mathrm{CAB}]_{t}$ represents the total $\mathrm{CAB}$ concentration in solution, then

$$
[\mathrm{CAB}]_{t}=\left[\mathrm{PhSO}_{2} \mathrm{NHCl}\right]+[\mathrm{X}]
$$

from which solving for $[\mathrm{X}]$ and substituting its value in (9), rate law (11) can be derived

$$
\text { rate }=\frac{K_{1} k_{2}[\mathrm{CAB}]_{t}[\mathrm{TCH}]}{1+K_{1}[\mathrm{TCH}]} .
$$

Rate law (11) is in good agreement with the experimental results.

Since rate $=k^{\prime}[\mathrm{CAB}]_{t}$, rate law (11) can be transformed into (12) and (13) as follows:

$$
\begin{gathered}
k^{\prime}=\frac{K_{1} k_{2}[\mathrm{TCH}]}{1+K_{1}[\mathrm{TCH}]}, \\
\frac{1}{k^{\prime}}=\frac{1}{K_{1} k_{2}[\mathrm{TCH}]}+\frac{1}{k_{2}} .
\end{gathered}
$$

Based on rate law (13), a plot of $1 / k^{\prime}$ versus $1 /[\mathrm{TCH}]$ at constant $[\mathrm{CAB}]_{0},\left[\mathrm{H}^{+}\right]$, and temperature was found to be linear (Figure $2 ; r=0.9934)$. From the intercept and slope of this plot, the formation constant $\left(K_{1}\right)$ and the decomposition constant $\left(k_{2}\right)$ of the substrate-oxidant species were found to be $10.9 \mathrm{dm}^{3} \mathrm{~mol}^{-1}$ and $6.67 \times 10^{-3} \mathrm{~s}^{-1}$, respectively.

3.1. Michaelis-Menten Kinetics. Since the rate was fractionalorder in $[\mathrm{TCH}]_{0}$, Michaelis-Menten type of kinetics [13] was adopted. The $\mathrm{TCH}$ was varied in the concentration range of $0.5 \times 10^{-2}-4.0 \times 10^{-2} \mathrm{~mol} \mathrm{dm}^{-3}$ at different temperatures $(283-313 \mathrm{~K})$, with all other experimental conditions being held constant. Based on (13), plots of $1 / k^{\prime}$ versus $1 /[\mathrm{TCH}]$ were found to be linear $(r>0.9851)$.

For a reaction involving a fast preequilibrium $\mathrm{H}^{+}$or $\mathrm{OH}^{-}$ ion transfer, the rate increases in $\mathrm{D}_{2} \mathrm{O}$ since $\mathrm{D}_{3} \mathrm{O}^{+}$and $\mathrm{OD}^{-}$ are 2 to 3 times stronger acids and stronger bases [12-14], respectively, than $\mathrm{H}_{3} \mathrm{O}^{+}$and $\mathrm{OH}^{-}$ions. The reverse holds good for reactions involving retardation of rate by $\mathrm{H}^{+}$or $\mathrm{OH}^{-}$ions. In the present case, solvent isotope studies show that $k^{\prime}\left(\mathrm{H}_{2} \mathrm{O}\right) / k^{\prime}\left(\mathrm{D}_{2} \mathrm{O}\right) \approx 1$ and this is generally correlated with the fact that the negligible effect of $\left[\mathrm{H}^{+}\right]$on the rate of reaction. Hence the observed solvent isotope effect supports the proposed mechanism and the derived rate expression.

The effect of varying solvent composition on the reaction kinetics has been described in detail in the well-known monographs [15-25]. For a limiting case of zero angle of approach between two dipoles or an ion-dipole system, Amis [23] has shown that a plot of $\log k^{\prime}$ versus $1 / D$ gives a straight line with a negative slope for a reaction between a negative ion and a dipole or between two dipoles, while a positive slope results for a positive ion-dipole interaction. The latter concept agrees with the present observations, where a positive ion and a dipole are involved in the rate-limiting step of Scheme 2.

The influence of the ionic strength of the medium on the rate is negligible indicating that nonionic species are involved in the rate limiting step. The reaction product, benzenesulfonamide $\left(\mathrm{PhSO}_{2} \mathrm{NH}_{2}\right)$, does not influence the rate showing that it is not involved in a preequilibrium. Addition of chloride ions had no effect on the rate indicating that no interhalogen or free chlorine is formed. All these observations also confirm the proposed mechanism.

The proposed mechanism is also supported by the moderate values of energy of activation and other activation parameters. The fairly high positive value of free energy of activation indicates that the transition state is highly solvated, while the large negative $\Delta S^{\neq}$suggests the formation of a compact activated complex with a reduction in the degrees of freedom of molecules.

\section{Conclusion}

The kinetics of oxidation of tetracaine hydrochloride by CAB has been studied at $303 \mathrm{~K}$. The reaction follows the rate law rate $=k[\mathrm{CAB}]_{\mathrm{o}}[\mathrm{TCH}]^{x}$, where $x$ is less than unity. On the basis of experimental results, a suitable mechanism and appropriate rate law have been derived. 
(i)<smiles>CCCCCCNc1ccc(C(=O)OCCN(C)C)cc1</smiles>

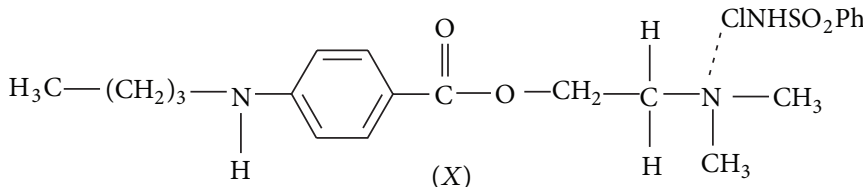

(ii)

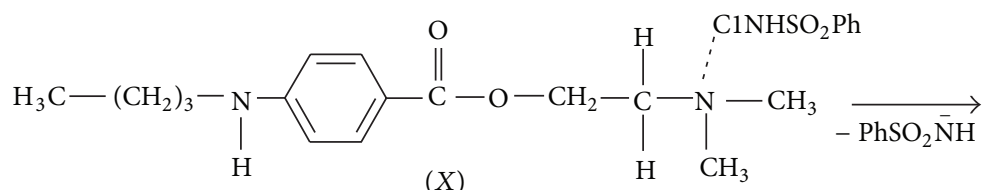<smiles>CCCCCCNc1ccc(C(=O)OCCC(C)[N+](C)(C)Cl)cc1</smiles>

$\left(X^{\prime}\right)$

(iii)
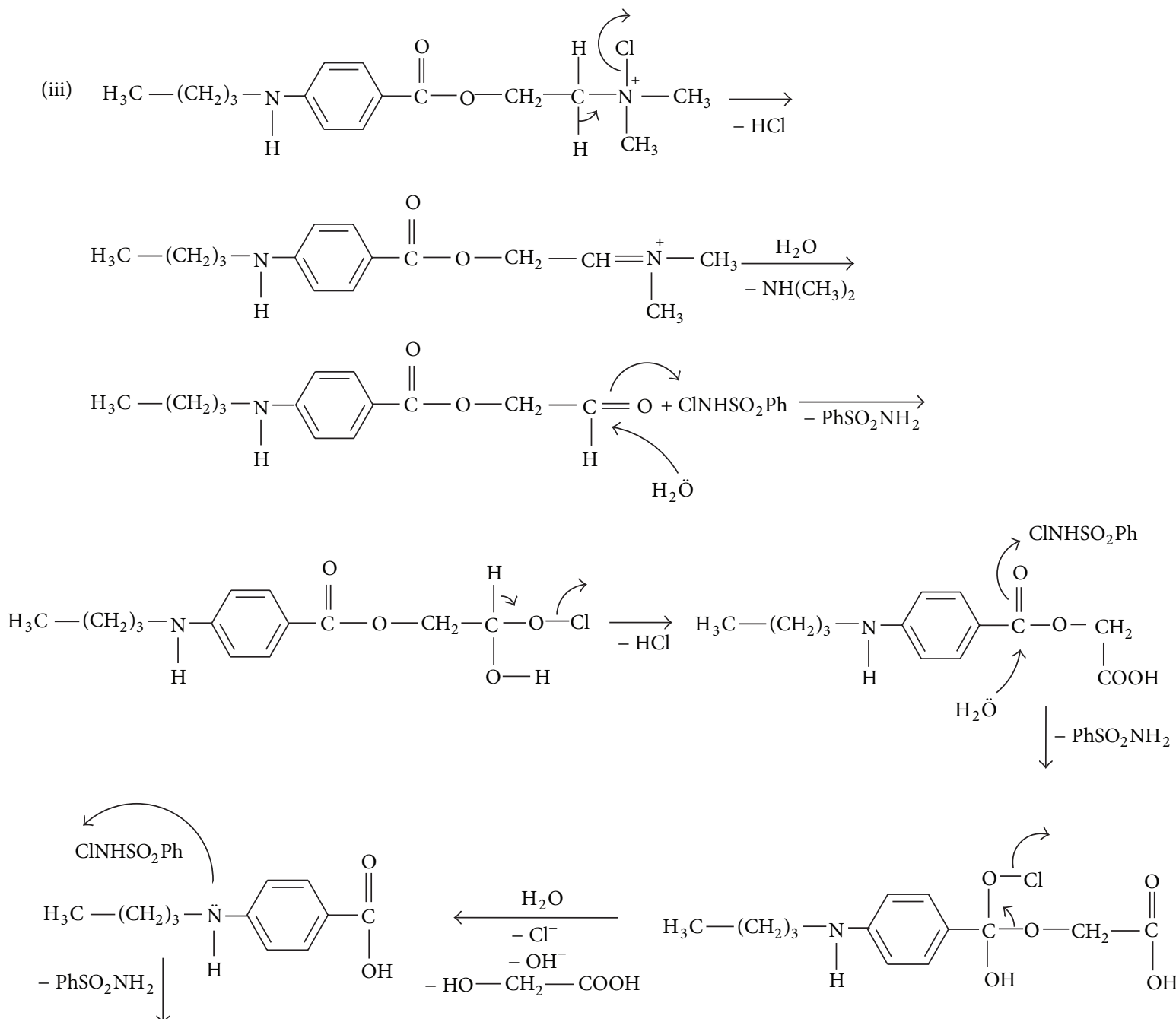


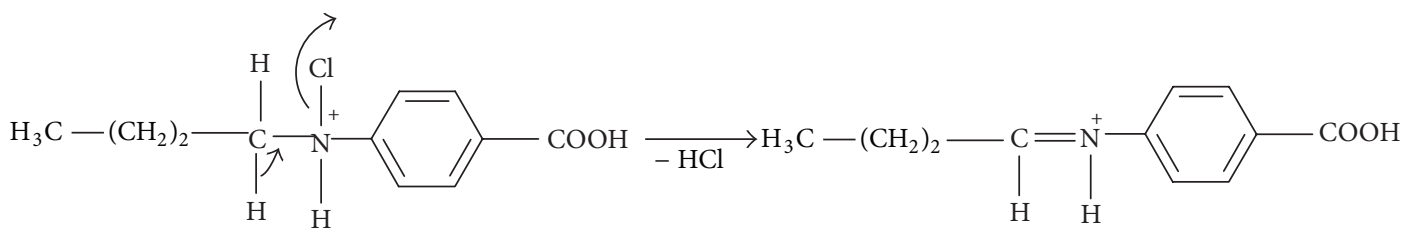<smiles>Nc1ccc(C(=O)O)cc1</smiles><smiles>CCCC(O)OCCCCC(=O)O</smiles>

Scheme 2: Detailed mechanistic interpretation of oxidation of tetracaine hydrochloride by $\mathrm{CAB}$ in $\mathrm{HClO}_{4}$ medium.

\section{Conflict of Interests}

The authors do not have any conflict of interests.

\section{Acknowledgments}

The authors are thankful to the Principal and the Management Don Bosco Institute of Technology for the facilities and encouragement.

\section{References}

[1] K. Ashutosh, Medicinal Chemistry, Wiley Eastern, New Delhi, India, 1993.

[2] C. O. Wilson, O. Gisvold, and R. F. Doerge, Wilson and Gisvold's Textbook of Organic Medicinal and Pharmaceutical Chemistry, J. B. Lippincott, Toronto, Canada, 6th edition, 1971.

[3] M. J. Cousins, Cousins and Bridenbaugh's Neural Blockade in Clinical Anesthesia and Pain, Lippincott Williams \& Wilkins, Toronto, Canada, 2008.

[4] M. M. Campbell and G. Johnson, "Chloramine T and related Nhalogeno-N-metallo reagents," Chemical Reviews, vol. 78, no. 1, pp. 65-79, 1978.

[5] K. K. Banerji, B. Jayaram, and D. S. Mahadevappa, "Mechanistic aspects of oxidations by N-metallo-N-haloarylsulphonamides," Journal of Scientific and Industrial Research, vol. 46, no. 2, pp. 65-76, 1987.

[6] M. C. Agarwal and S. K. Upadhyay, "Mechanistic investigations involving chloramine-T," Journal of Scientific and Industrial Research, vol. 49, pp. 13-18, 1990.

[7] X. L. Armesto, L. M. Canle, M. V. García, and J. A. Santaballa, "Aqueous chemistry of N-halo-compounds," Chemical Society Reviews, vol. 27, no. 6, pp. 453-460, 1998.
[8] E. E. Kolvari, A. Ghorbani-Choghamarani, P. Salehi, F. Shirini, and M. A. Zolfigol, "Application of N-halo reagents in organic synthesis," Journal of the Iranian Chemical Society, vol. 4, no. 2, pp. 126-174, 2007.

[9] G. Akerloff, "Dielectric constants of some organic solvent-water mixtures at various temperatures," Journal of the American Chemical Society, vol. 54, no. 11, pp. 4125-4139, 1932.

[10] P. Puttaswamy, A. Sukhdev, and J. P. Shubha, "Kinetics and reactivities of ruthenium(III)- and osmium(VIII)-catalyzed oxidation of ornidazole with chloramine-T in acid and alkaline media: a mechanistic approach," Journal of Molecular Catalysis A, vol. 310, no. 1-2, pp. 24-33, 2009.

[11] P. Puttaswamy, A. Sukhdev, and J. P. Shubha, "Palladium(II)catalyzed oxidation of tranexamic acid by bromamine- $\mathrm{B}$ in alkaline medium and uncatalyzed reaction in acid medium: a study of kinetic and mechanistic chemistry," Journal of Molecular Catalysis A, vol. 332, no. 1-2, pp. 113-121, 2010.

[12] A. R. V. Murthy and B. S. Rao, "Oxidation by chloramine-T. Part II. Redox potential of chloramine-T-sulfonamide systems," Proceedings of the Indian Academy of Science, vol. 35, pp. 69-72, 1952.

[13] J. E. House, Principles of Chemical Kinetics, Academic Press, 2007.

[14] J. C. Morris, J. R. Salazar, and M. A. Winemann, "Equilibrium studies on N-chloro compounds. I. The ionization constant of N-chloro-p-toluenesulfonamide," Journal of the American Chemical Society, vol. 70, no. 6, pp. 2036-2041, 1948.

[15] E. Bishop and V. J. Jennings, "Titrimetric analysis with chloramine-T-I. The status of chloramine-T as a titrimetric reagent," Talanta, vol. 1, no. 3, pp. 197-212, 1958.

[16] F. F. Hardy and J. P. Johnston, "The interaction of N-bromo-Nsodiobenzenesulphonamide (bromamine B) with p-nitrophenoxide ion," Journal of the Chemical Society, Perkin Transactions 2, no. 6, pp. 742-746, 1973. 
[17] K. Higuchi, K. Ikeda, and A. Hussain, "Mechanism and thermodynamics of chlorine transfer among organochlorinating agents. Part III. Autocatalytic pathway between N-chlorosuccinimide and chloramine-T,' Journal of the Chemical Society B, pp. 1031-1036, 1968.

[18] C. J. Collins and N. S. Bowman, Isotope Effects in Chemical Reactions, Van Nostrand Reinhold, New York, NY, USA, 1970.

[19] A. Kohen and H. H. Limbach, Isotope Effects in Chemistry and Biology, CRC Press, Florida, Fla, USA, 2006.

[20] K. B. Wiberg, Physical Organic Chemistry, Wiley, New York, NY, USA, 1964.

[21] K. J. Laidler, Reaction Kinetics, Pergamon, New York, NY, USA, 1963.

[22] J. C. House, Principles of Chemical Kinetics, Wm. C. Brown, Boston, Mass, USA, 1997.

[23] E. S. Amis, Solvent Effects on Reaction Rates and Mechanisms, Academic Press, New York, NY, USA, 1966.

[24] E. A. Molewyn-Hughes, The Kinetics of Reaction in Solutions, Clarendon Press, Oxford, UK, 1947.

[25] E. A. Molewyn-Hughes, Physical Chemistry, Pergamon, New York, NY, USA, 2nd edition, 1961. 

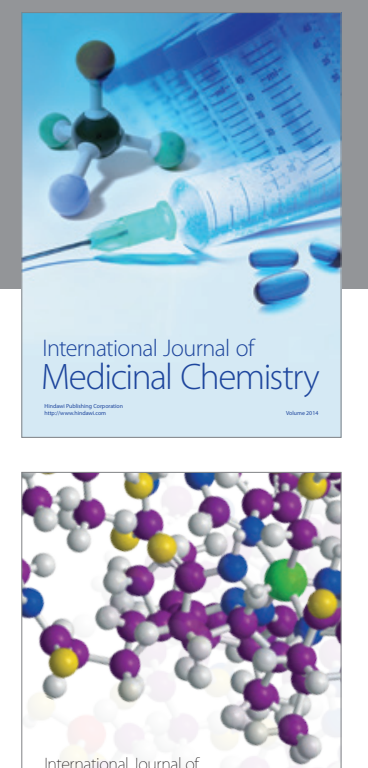

\section{Carbohydrate} Chemistry

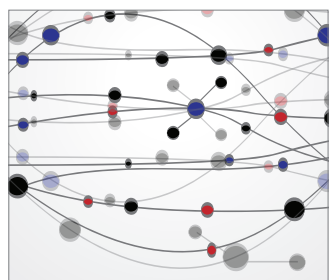

The Scientific World Journal
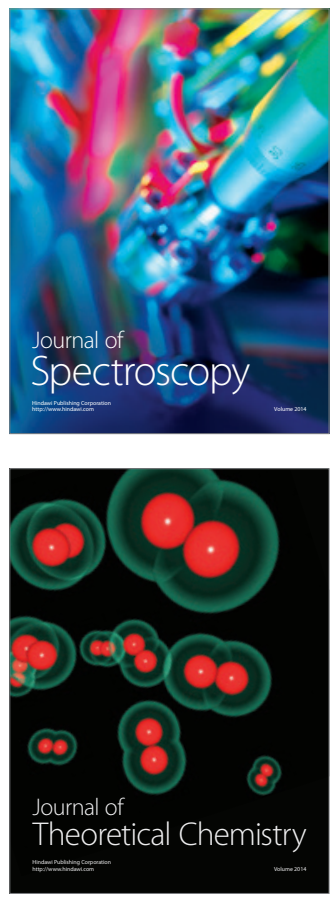
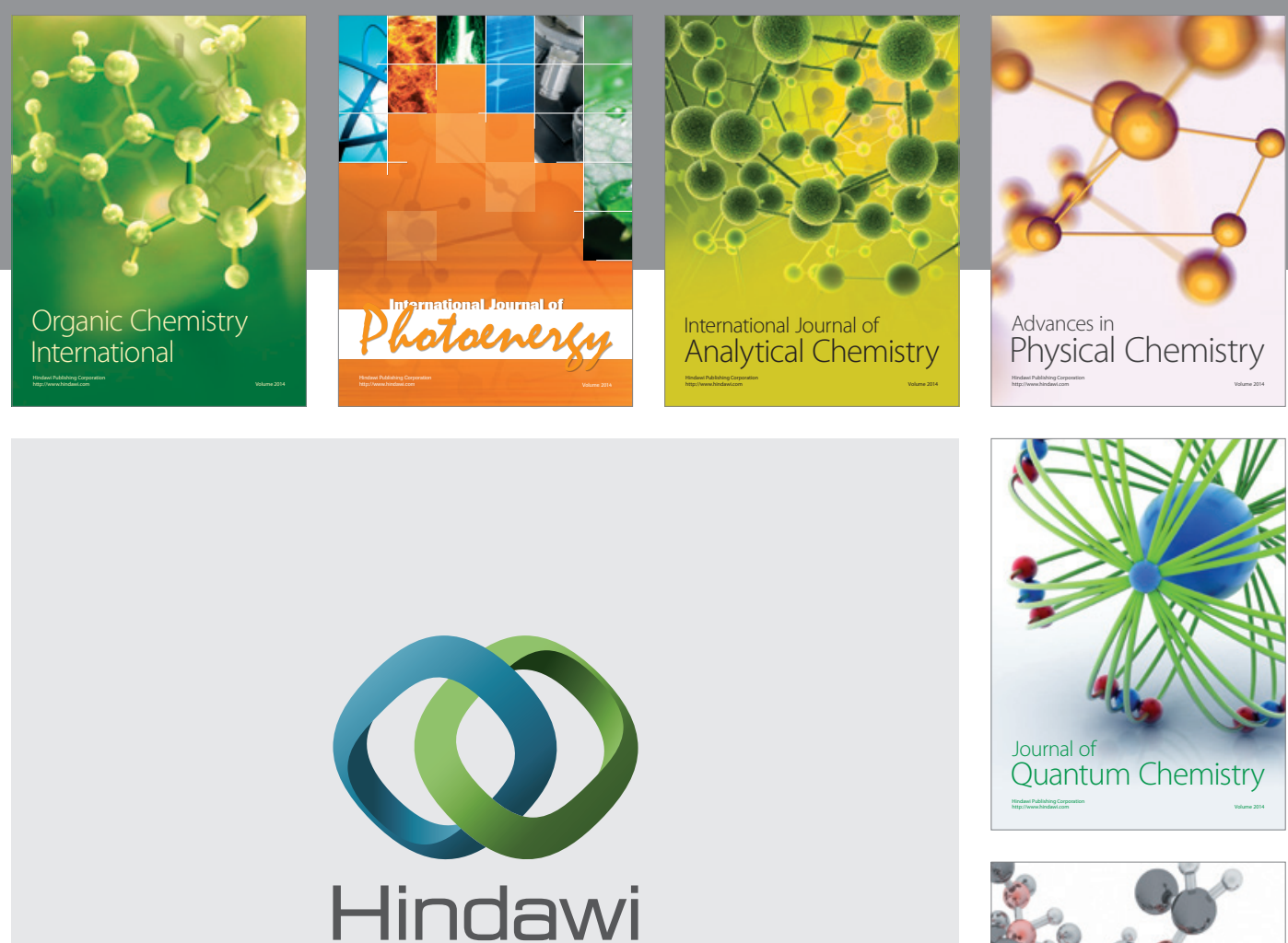

Submit your manuscripts at

http://www.hindawi.com

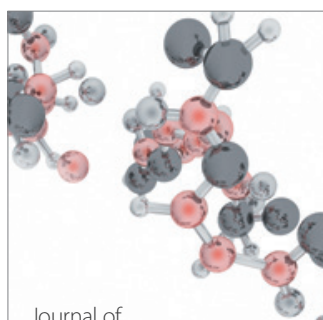

Analytical Methods

in Chemistry

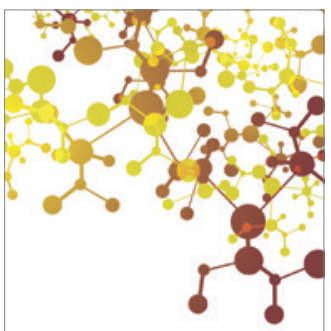

Journal of

Applied Chemistry

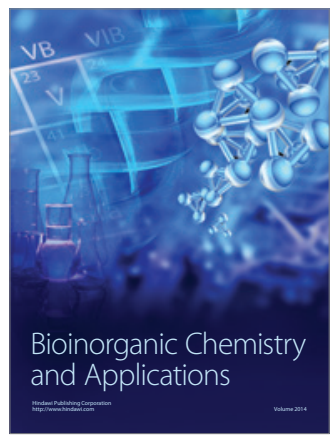

Inorganic Chemistry
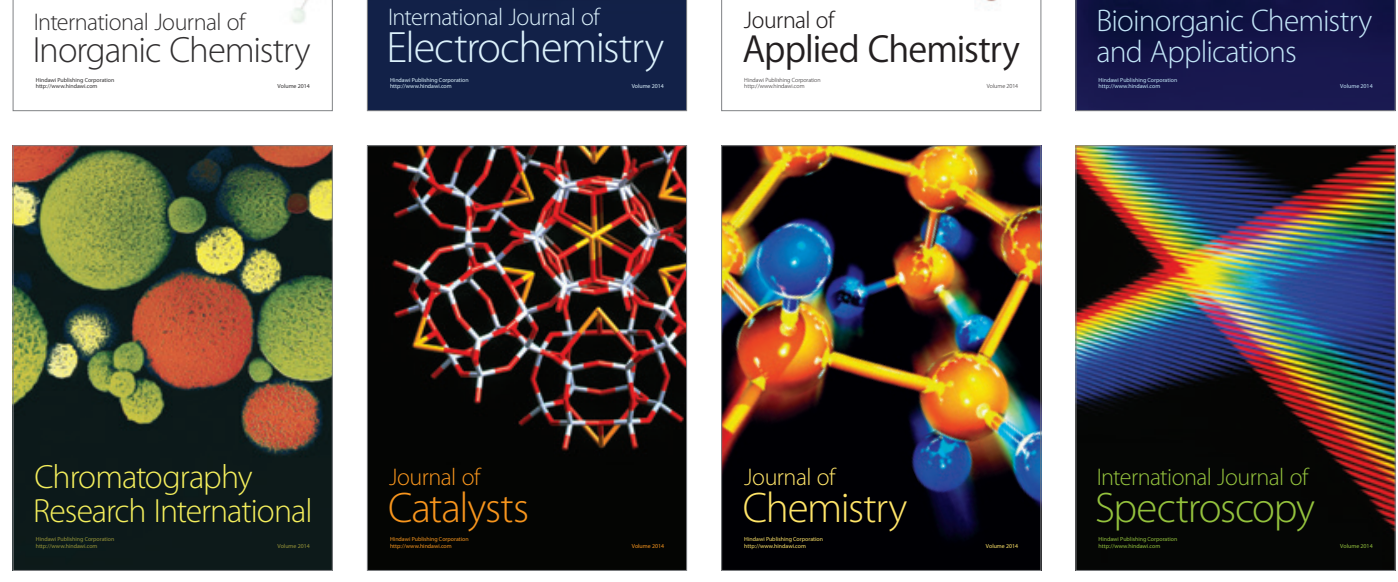